of the vein to the radial artery may be less likely to cause this complication than the side-to-side anastomosis normally performed by our surgical colleagues.

Detailed results of our studies are now being submitted for publication.-We are, etc.,

DAVID J. WARREN L. S. OTIENO

Medical Renad Unit Department of Medicine, Royal Infirmary, Bdinburgh

\section{Cost of Part II M.R.C.P.}

SIR,-On scrutinizing application forms for entry to the part II M.R.C.P. (U.K.) examination I was astounded to note that the entry fee has just been increased to $£ 60$ "to cover rising cost of administration." Since in 1972 the fee was $£ 35$ this. represents an increase of $71 \%$, far outstripping the national rate of inflation over these two years. If I should be so lucky as to pass the examination then I would be accorded the dubious privilege of paying the colleges a funther $£ 30$ for the diploma, making $£ 90$ in all for passing part II M.R.C.P.

Like many young doctors I find it a struggle to bring up my family, pay the mortgage, and yet remain financially solvent. Should the fees continue to escalate in this appalling manner then the financial deterrent to taking the M.R.C.P. which they will impose will mean that future aspirants to membership of the colleges will be confined to those with private means. - I am, etc.,

Bude, Cornwall

M. R. THOMSON

\section{Tuberculous Polyradiculitis}

SIR,-An association of the Guillain-Barré syndrome with infectious agents is well documented, ${ }^{1-4}$ and Leneman $^{5}$ found an association with infective disease in 638 out of 1,100 cases collected from the literature, but the fortuitous nature of this association is borne out by the non-specific pathological findings. A polyradiculitis caused by a specific infection is not unknown, however, and will produce the same neurological picture. We here report a case in which tuberculous granulomata and the tubercle bacillus were demonstrated in the nerve roots at necropsy in a patient who presented with the salient features of the GuillainBarré syndrome.

A 10-year-old boy who had suffered from a brief febrile illness without neurological or respiratory manifestations two weeks previously was admitted to hospital with difficulty in passing urine. On the following day he developed weakness of the right leg and, a few hours later, of the left leg. The lower limbs were flaccid and areflexic, with absent plar limbs were flaccid and areflexic, with absent plantar responses. The upper limbs showed no abnormality. He was very irritable and had generalized hyperaesthesia which made sensory testing difficult. Lumbar puncture revealed a viscid, xanthochromic fluid with a protein content of $4.5 \mathrm{~g} / 100 \mathrm{ml}$ and 20 lymphocytes $/ \mathrm{mm}^{3}$. During the next 36 hours he developed a rapidly ascending paralysis with fiaccid, hyporeflexic upper limbs. Lumbar puncture was repeated and yielded C.S.F. with a protein content of $3.5 \mathrm{~g} / 100 \mathrm{ml}$ and 22 lymphocytes $/ \mathrm{mm}^{3}$; there were no acidefast bacilli. His condition remained unchanged for 36 hours but the next day he unchanged for 36 hours but the next
developed a tachycardia and died suddenly.

At necropsy the interpeduncular fossa and the spinal cord were covered with a thick, gelatinous exudate resembling coagulated plasma. The rest of the surface of the brain appeared normal. No

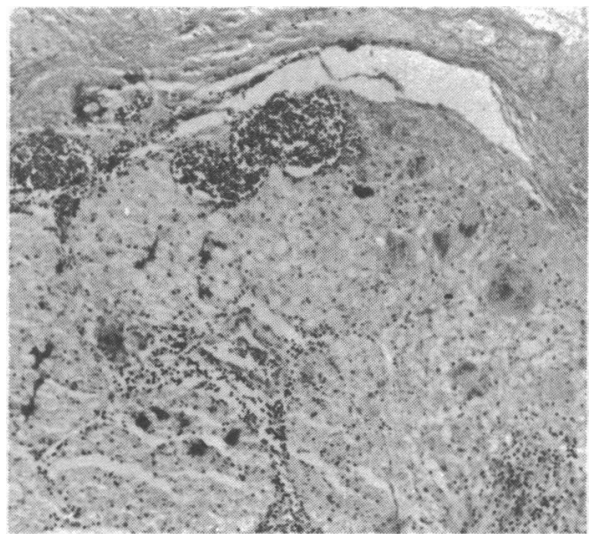

Fig. 1-Section of nerve root showing tuberculous granulomata, mononuclear cell infiltrate, and swelling and destruction of myelinated nerve fascicul with lipid phagocytes.

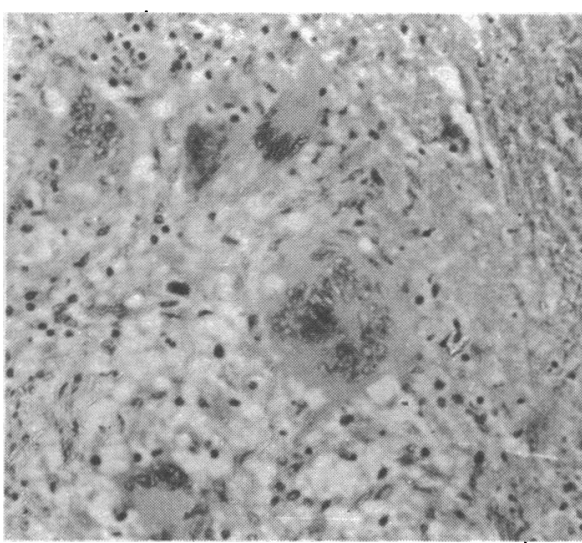

Fig. 2-High power field of nerve root section.

abnormality was seen in coronal sections of the brain and spinal cord other than the subarachnoid coagulum enveloping the brain stem and spina cord. In histological sections a few small tuberculous granulomata were seen in the fibrinous exudate in the interpeduncular and spinal subarachnoid in the interpeduncular and spinal subarachnoid space. The basal and spinal leptomeninges were parsely infiltrated with mononuclear cells, mostly rymphocytes. The anterior and posterior nerve roots in the cervical, thoracic, and lumbosacral
regions were swollen and infiltrated with monoregions were swollen and infiltrated with mono-
nuclear cells, mostly lymphocytes. Many of the nerve roots showed tuberculous granulomat (some with caseation) and swelling and destruction of myelinated nerve fasciculi with lipid phagocytes in relation to them (see figs). Small perivascular collections of lymphocytes and swelling and vacuolation of some ganglion cells were seen in the posterior root ganglia. Acid-fast bacilli, morphoposterior root ganglia. Acid-fast bacill, morphosome nerve roots and in the exudate in the interpeduncular fossa.

There was no evidence of an inflammatory process in the peripheral nerves examined. Wallerian degeneration of axons and myelin in scattered fibres in peripheral nerves was seen in sections and teased nerve preparations. No evidence, and teased nerve preparations. No evidence, other disease was seen in the lungs, heart, liver, other disease was seen in the lungs, heart,
kidneys, spleen, lymph nodes, or adrenals.

The occurrence of radiculomyelopathy in tuberculous meningitis is not well recog nized, but has been reported by Wadia. ${ }^{6}$ In the present case differential involvement of the nerve roots by tuberculous granulomata was unequivocally demonstrated and accounted for the rapid centripetal spread of paralysis simulating the Guillain-Barré syndrome. The possibility of such an association should evidently be borne in mind in the differential diagnosis of a puzzling radiculopathy in communities where tuberculous meningitis is not uncommon.-We are, etc.,

J. B. Peiris

H. R. WICKREMASINGHE M. A. CHANDRASEKARA

General Hospital,

1 Haymaker, $W$, and Kernohan, J. W., Medicine, Haymaker, W., and Kernohan, J. W., Medicine, Milier, H., Proceedings of the Royal Society of Campbell, A. M. G., Proceedings of the Royal Society of Medicine, 1958, 51, 157. A. British Chanmugan, D., and Wani

5 Leneman, F., Archives of Internal Medicine, 1966, 118, 139.

Wadia, N. H., in Tropical Neurology, ed. J. D. 1973.

\section{Hernias in Children}

SIR,-In your leading article on this subject (31 August, p. 540) I was sumprised that no mention was made of the Edinburgh skeinof-wool treatment. If this method is used by intelligent parents a cure can be effected since, as you yourself say, the tendency is for the processus vaginalis to close spontaneously.

An eight-stranded loop of knitting wool, long enough to go round the pelvis and perineum, is placed around the pelvis with the index finger through the loop of one end and holding the hernia in. The other end is looped through this sufficiently tightly to keep the hernia in and then taken round the perineum to be looped into the wool at the back.-I am, etc.,

\section{J. R. Crumbie}

Croydon, Surrey

\section{Larrey and Débridement}

SIR,-Mr. D. H. Patey's letter on débridement (14 September, p. 686) makes it quite clear that this procedure was originally only an apening up of the wound. It was employed in this way especially in the first world war in order to gain better acoess for antiseptics. Deliberate excision of damaged tissue followed more or less accidentally as a natural extension of débridement only towards the end of the war.

Primary excision of wounds as a deliberate operation instead of débridement was first described by Milligan in 1915.1 In this article Milligan described the modern operation of wound excision and emphasized that removal of damaged tissue is far more im portant than the instillation of antiseptics. His paper was based on eight months' experience of war wounds so that he must have employed the operation almost from the outbreak of war. This remarkable article was years ahead of its time. It occupies only one half-page of the B.M.f. and it contains all the essentials of the modern operation. I have found only one reference ${ }^{2}$ to this classic article and it has been sadly overlooked, but it establishes Milligan as the pioneer of primary excision of wounds.-I am, etc.,

Grorgr QVIST

London $\mathbf{W} .1$

1 Milligan, B. T. C., British Medical Yournal, 1915, 1,1081

2 Downes, R. M., Yourmal of the Royal Army 